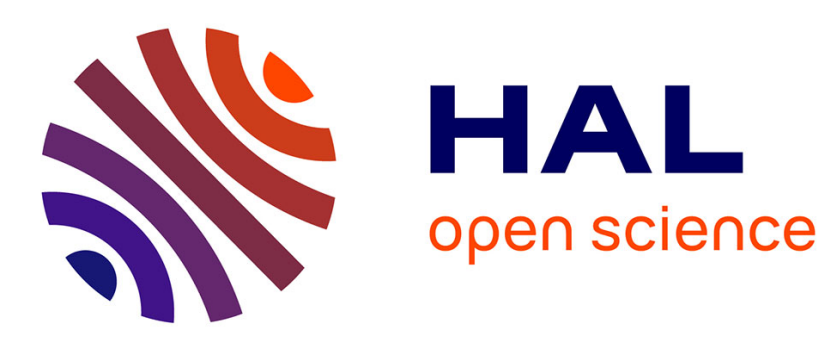

\title{
Multiple-Scattering Extended X-Ray Absorption Fine Structure Analysis of Spinel Ferrites
}

\author{
V. Harris, C. Williams, M. Abe, Q. Zhang
}

\section{To cite this version:}

V. Harris, C. Williams, M. Abe, Q. Zhang. Multiple-Scattering Extended X-Ray Absorption Fine Structure Analysis of Spinel Ferrites. Journal de Physique IV Proceedings, 1997, 7 (C2), pp.C2-1155C2-1156. 10.1051/jp4:19972170 . jpa-00255235

\section{HAL Id: jpa-00255235 https://hal.science/jpa-00255235}

Submitted on 1 Jan 1997

HAL is a multi-disciplinary open access archive for the deposit and dissemination of scientific research documents, whether they are published or not. The documents may come from teaching and research institutions in France or abroad, or from public or private research centers.
L'archive ouverte pluridisciplinaire HAL, est destinée au dépôt et à la diffusion de documents scientifiques de niveau recherche, publiés ou non, émanant des établissements d'enseignement et de recherche français ou étrangers, des laboratoires publics ou privés. 


\title{
Multiple-Scattering Extended X-Ray Absorption Fine Structure Analysis of Spinel Ferrites
}

\author{
V.G. Harris, C.M. Williams*, M. Abe** and Q. Zhang** \\ U.S. Naval Research Laboratory, Washington, DC 20375, U.S.A. \\ * Morgan State University, Baltimore, MD 21339, U.S.A. \\ ** Tokyo Institute of Technology, Okayama, Meguro-ku, Tokyo 152, Japan
}

\begin{abstract}
We have applied extended X-ray absorption fine structure (EXAFS) spectroscopy to study the cation distribution in a series of spin-sprayed NiZn-ferrite films. A least-squares fitting of experimental EXAFS data with theoretical, multiplescattering, EXAFS data allowed the quantitative determination of site distributions for all transition metal cations.
\end{abstract}

In recent years there has been a resurgence in the study of spinel ferrites largely fueled by the need for high-quality, lowloss, films for the development of monolithic magnetic integrated-circuit devices. Because samples grown via vapor-quenching techniques are typically not at equilibrium, trends derived from experiments on bulk ferrite samples cannot be extrapolated to thin films. As a result, the careful characterization of thin film ferrites is essential. For spinel oxides the cation filling of the octahedral and tetrahedral sites strongly influences the materials' magnetic and electronic properties. Probes that can provide this type information include X-ray [1] and neutron diffraction [2], and Mossbauer effect (ME) [3]. However, techniques which are useful for the characterization of bulk materials are often of limited use when it comes to thin films because of the small masses intrinsic to these samples. This problem is compounded when information on dilute additives is the focus. In this paper, we describe the use of extended X-ray absorption fine structure (EXAFS) as a tool to study the site distribution of cations in ferrite films.

Samples studied here are spin-sprayed [4] NiZn-ferrite films $(t=0.5 \mu \mathrm{m})$, where the Ni concentration is fixed and the $\mathrm{Zn}$ concentration is varied at the expense of the Fe. The films were deposited onto glass substrates with compositions: $\mathrm{Ni}_{0.15} \mathrm{Zn}_{\mathrm{y}} \mathrm{Fe}_{2.85-\mathrm{y}} \mathrm{O}_{4}(\mathrm{y}=0.16,0.23,0.40,0.60)$. Powder samples of $\mathrm{ZnFe} 2 \mathrm{O}_{4}, \mathrm{NiFe}_{2} \mathrm{O}_{4}$, and Fe3 $\mathrm{O}_{4}$ were studied as empirical standards for use in the EXAFS modeling analysis.

EXAFS data collection was performed using the total electron-yield (TEY) detection scheme $[5,6]$ on the X23B beamline at the National Synchrotron Light Source, operating at a maximum ring current of $230 \mathrm{~mA}$ and a minimum of $110 \mathrm{~mA}$. The X23B beamline employs a double-crystal, fixed-exit, $\mathrm{Si}$ (111) monochromator with a collimating mirror for harmonic rejection. The EXAFS analysis followed established procedures[7], which included the normalization of the extended fine structure to the absorption edge step height and energy, removal of a non-oscillatory background curvature, conversion to photoelectron wave vector $(k)$ space, and Fourier transformation to radial $(r)$ coordinates Data collected from standards of $\mathrm{Fe}_{3} \mathrm{O}_{4}, \mathrm{ZnFe}_{2} \mathrm{O}_{4}$, and $\mathrm{NiFe}_{2} \mathrm{O}_{4}$ were similarly analyzed. In addition, theoretical EXAFS data, generated using the multiplescattering FEFF (v.6.01) codes [8, 9], were similarly analyzed and used in least-squares fitting the unknown EXAFS data to determine the fractional site occupancy of the absorbing cations. Henceforth, data generated from these codes will be referred to as FEFF data.

Figure 1(a) is a plot of the Fe EXAFS collected from the $\mathrm{Ni}_{0.15} \mathrm{Zn}_{0.16} \mathrm{Fe}_{2.69 \mathrm{O}_{4}}$ sample in $k$-space. Error bars plotted on these data represent the standard deviation from a mean calculated by merging five data sets in $k$-space. As such, these bars represent both the statistical uncertainty in data collection, and the uncertainty introduced to the data via the fitting and removal of a cubic spline curve in the background removal procedure. Figure 1(b) is a plot of the Fourier transformed Fe EXAFS collected from the four $\mathrm{Nio} .15 \mathrm{Zn}_{\mathrm{y}} \mathrm{Fe}_{2.85-\mathrm{y}} \mathrm{O}_{4}$ samples. These data have all been analyzed using identical parameters and plotted on the same $\mathrm{x}$ - and $\mathrm{y}$-axes to allow direct comparisons between sample sets. By comparing these data it is clear that the amplitudes of the Fourier features vary from sample to sample in a systematic manner. Upon close inspection, one sees that the variations are largest in the first three peaks of the Fourier transforms. The large asymmetric peak centered near $1.5 \AA$ corresponds with the two Fe-O bond distances corresponding to the Fe ions on the A- and B-sites.[10, 11] The large split peak centered near $2.9 \AA$ corresponds with several different atom pair correlations, as well as multiple-scattering (MS) contributions.[10, 11] The low-r split peak $(2.5 \AA)$ includes contributions from the $F_{B}-M_{B}(M ;$ metal cation) correlations. In contrast, the high- $r$ split peak includes contributions from $\mathrm{Fe}_{\mathrm{A}}-\mathrm{M}_{\mathrm{A}}, \mathrm{Fe}_{\mathrm{A}}-\mathrm{O}, \mathrm{Fe}_{\mathrm{A}}-\mathrm{M}_{\mathrm{B}}$, and $\mathrm{Fe} \mathrm{B}-\mathrm{O}$ correlations [10, 11]: About $12 \%$ of this peak's amplitude arises from MS contributions. In this panel the high-r split peak (3.1 $\AA$ ) increases in amplitude with decreasing $\mathrm{Zn} / \mathrm{Fe}$ while the low- $r$ split peak shows the opposite trend. The peak centered near $1.5 \AA$ decreases in amplitude with decreasing $\mathrm{Zn} / \mathrm{Fe}$. All of these trends can be qualitatively explained by the site distribution of the $\mathrm{Zn}$ and Fe cations. When $\mathrm{Zn}$ is added to the sample it preferentially occupies the A-sites. This forces a larger fraction of Fe ions to occupy the Bsites. The oxygen peak varies in amplitude due to the change in occupancy between the 6-fold coordination B-site and the 4fold coordination A-site. The split-peak near $2.9 \AA$ reflects this distribution more directly. 


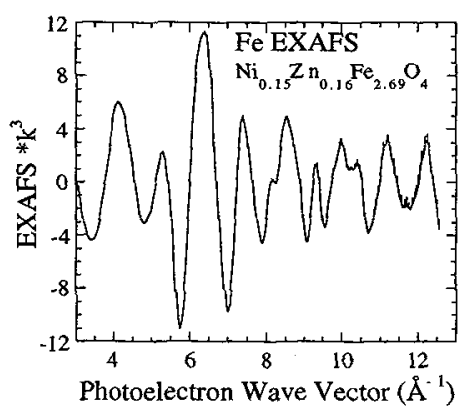

(a)

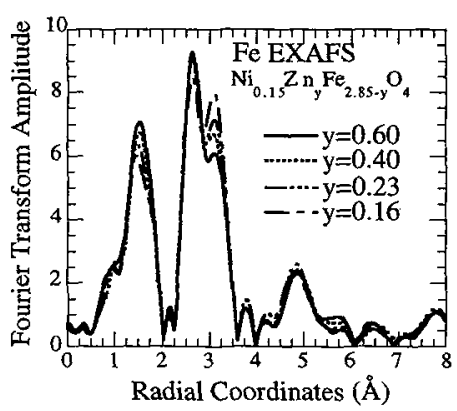

(b)

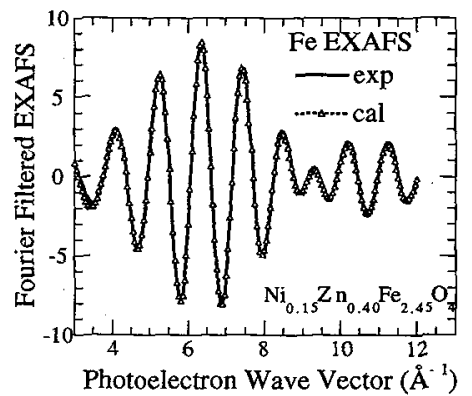

(c)

Figure 1. (a) Normalized Fe K EXAFS in $k$-space for the Ni0.15 $\mathrm{Zn}_{0.16} \mathrm{Fe}_{2.69} \mathrm{O}_{4}$ sample. Error bars are plotted on the data to represent the statistical uncertainty and that introduced to the data via the background removal procedure. (b) Fourier transformed

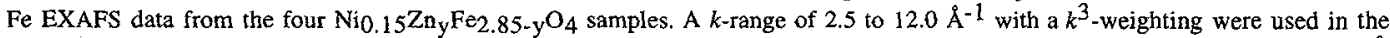
transformation. (c) Fourier-filtered EXAFS data with best fit for the $\mathrm{Ni}_{0} .15 \mathrm{Zn}_{0.40} \mathrm{Fe}_{2.45} \mathrm{O}_{4}$ sample. An $r$-space range of 2 - $3.6 \AA$ was Fourier-filtered. The best fit was determined by a least-squares fitting of the data using multiple-scattering, simulated XAFS data generated using FEFF 6.01 codes.

To quantitatively measure the distribution of cations we least-squares fit the unknown data with FEFF data using the fractional occupancy of the A- and B-sites as the only adjustable parameter: All other parameters are calculated $a b$ initio via the FEFF codes. Specifically, the $r$-space region extending from $2.0-3.6 \AA$, for both the unknown EXAFS and the FEFF data, was Fourier-filtered to $k$-space. Least-squares fitting was performed to phase and amplitude in $k$-space. Fig. 1(c) is a plot of the Fourier-filtered Fe EXAFS for the Ni0.15 $\mathrm{Zn}_{0.40} \mathrm{Fe}_{2.45} \mathrm{O}_{4}$ sample with the best fit using a combination of $\mathrm{A}$ - and $\mathrm{B}$-site $\mathrm{Fe}$ FEFF data. Fitting of the standards was performed prior to fitting the unknown. The fitting of the standards was necessary in this case because it allowed for the refinement of the EXAFS Debye temperature and the vo corrections. The amplitude reduction coefficient, $\mathrm{S}_{0}{ }^{2}$, was fixed at 0.9 for all FEFF calculations. Consistent with our interpretation of the qualitative trends observed in Fig. 1(b), the quantitative analysis indicates that the fractional filling of Fe on the B-site increases with increasing $\mathrm{Zn} / \mathrm{Fe}$. This result is consistent with trends measured in bulk $\mathrm{Zn}$-ferrites by Hastings and Corless [12] who found $\mathrm{ZnFe}_{2} \mathrm{O}_{4}$ to be a normal spinel, meaning that the 8 divalent $\mathrm{Zn}$ cations reside on the A-sites while both divalent and trivalent Fe cations fill the B-sites. Alternatively, we find that the Ni cations preferentially fill the B-sites but also fill the A-sites with increasing $\mathrm{Zn} / \mathrm{Fe}$. This is contrary to trends measured in bulk $\mathrm{NiFe}_{2} \mathrm{O}_{4}$, which was found to be an inverse spinel having divalent $\mathrm{Ni}$ cations filling the $\mathrm{B}$-sites, with divalent and trivalent $\mathrm{Fe}$ filling both the $\mathrm{A}$-sites and the remaining $\mathrm{B}$-sites

\section{Acknowledgments}

This research was carried out, in part, at the National Synchrotron Light Source (Brookhaven National Laboratories, Upton, NY), which is sponsored by the U.S. Department of Energy.

\section{References}

[1] A. Claasen, Proc. Phys. Soc., 38, (1925-1926), 482.

[2] C. G. Shull, E. O. Wollan, and W. C. Koehler, Phys. Rev., 84, (1951), 912.

[3] G. K. Wertheim, J. Appl. Phys., 32, (1961), 110S.

[4] M. Abe and Y. Tamaura, J. Appl. Phys., 55, (1984), 2614.

[5] A. Erbil, G. S. Cargill III, R. Frahm, and R. F. Boehme, Phys. Rev., B37, (1988), 2450.

[6] W. T. Elam, J. P. Kirkland, R. A. Neiser, and P. D. Wolf, Phys. Rev., B38, (1988), 26.

[7] D. E. Sayers and B. A. Bunker, in X-ray Absorption:Principles, Applications, Techniques of EXAFS, SEXAFS and XANES, D. C. Koningsberger and R. Prins, Eds. New York: Wiley, 1988, pp. 211.

[8] J. J. Rehr, J. M. d. Leon, S. I. Zabinsky, and R. C. Albers, J. Amer. Chem. Soc., 113, (1991), 5135.

[9] J. J. Rehr, S. I. Zabinsky, and R. C. Albers, Phys. Rev. Lett., 69, (1992), 3397.

[10] V. G. Harris, N. C. Koon, C. M. Williams, Q. Zhang, M. Abe, J. P. Kirkland, and D. A. McKeown, IEEE Trans. on Magn., 31, (1995), 3473.

[11] V. G. Harris, N. C. Koon, C. M. Williams, Q. Zhang, M. Abe, and J. P. Kirkland, Appl. Phys. Lett., 68, (1996), 2082.

[12] J. M. Hastings and L. M. Corless, Rev. Mod. Phys., 25, (1953), 114. 